\title{
A PRESENÇA DA PSICANÁLISE NA UNIVERSIDADE FRANCESA
}

THE PRESENCE OF PSYCHOANALYSIS IN THE FRENCH UNIVERSITY

LA PRESENCIA DEL PSICOANÁLISIS EN LA UNIVERSIDAD FRANCESA

\author{
Camila Santos Lima Fonteles \\ Denise Maria Barreto Coutinho*
}

\begin{abstract}
RESUMO
Este artigo tem o objetivo de retraçar o percurso da Psicanálise na universidade francesa, apresentando um panorama de sua atual conformação, com destaque para as produções psicanalíticas das universidades Paris VII e Paris VIII, pioneiras na inserção da Psicanálise no ambiente universitário do país. Para tal fim, percorremos a história da Psicanálise na universidade, na França, desde os estudos de Freud com Charcot até a criação dos dois Departamentos de Psicanálise. Em seguida, realizamos um levantamento das teses produzidas entre 1987 e 2012 nas referidas instituições francesas, com exame de temas, métodos e referenciais teóricos. Como resultado dessa investigação, estimamos ter oferecido uma dimensão compreensiva à relação entre Psicanálise e universidade. Além disso, o exame da produção ao longo de mais de duas décadas pode fornecer um panorama específico do campo psicanalítico universitário francês, com o qual o Brasil sempre manteve relações de intenso intercâmbio e proximidade.
\end{abstract}

Palavras-chave: Psicanálise na França. História da Psicanálise. Teses psicanalíticas. Estudos sobre a universidade.

\begin{abstract}
This article aims to retrace the path of psychoanalysis in the French university presenting an overview of its current conformation, especially the psychoanalytic productions of the Paris VII and Paris VIII universities, pioneers in the introduction of psychoanalysis in the university environment nationwide. Having that in mind, we went through the history of psychoanalysis in the university, in France, from Freud's studies together with Charcot until the creation of the two Departments of Psychoanalysis. Then we carried out a survey on the thesis produced from 1987 to 2012
\end{abstract}

\footnotetext{
Texto recebido em 28 de abril de 2016 e aprovado para publicação em 18 de novembro de 2016.

* Doutora em Psicologia pela Universidade Federal da Bahia (UFBA) e Université Paris Diderot - Paris VII, psicóloga. Endereço: Rua Cayowaá, 2197, apto 104, Sumaré São Paulo-SP, Brasil. CEP 01258-011. E-mail: camilafonteles@hotmail.com.

** Doutora em Letras pela UFBA/Princeton University, professora associada na UFBA, docente permanente do Programa de PósGraduação em Artes Cênicas e do PPG em Psicologia, ambos da UFBA, graduada em Psicologia. Endereço: Rua Waldemar Falcão, 641, apto 501 - Brotas, Salvador-BA, Brasil. CEP: 40295-010. E-mail: denisecoutinho1@gmail.com.
} 
at these French institutions, with subsequent analysis of its themes, methods and theoretical frameworks. As a result from this research, we presume to have offered a comprehensive dimension of the relationship between psychoanalysis and university. In addition, the examination of the production over more than two decades can provide a specific picture of the French psychoanalytic field in the university, with which Brazil has always kept intensive exchange and close relationship.

Keywords: Psychoanalysis in France. History of psychoanalysis. Psychoanalytic thesis. University studies.

\section{RESUMEN}

Este artículo tiene como objetivo trazar el camino del psicoanálisis en la universidad francesa presentando una visión general de su conformación actual, con especial atención a las producciones psicoanalíticas de las Universidades de Paris VII y de Paris VIII, pioneras en la integración del psicoanálisis en el ámbito universitario del país. Con este fin, vamos a través de la historia del psicoanálisis en la universidad francesa desde los estudios de Freud con Charcot a la creación de dos Departamentos de Psicoanálisis. A continuación, se realizó una encuesta de tesis producidas entre 1987 y 2012 en estas instituciones, con exámenes de los temas, métodos y marcos teóricos. Como resultado de esta investigación, se espera que hemos ofrecido una dimensión global a la relación entre el psicoanálisis y la universidad. Por otra parte, el examen de la producción durante más de dos décadas puede proporcionar una visión específica del campo psicoanalítico en la universidad francesa, con el cual Brasil siempre ha mantenido un intenso intercambio y relaciones cercanas.

Palabras clave: Psicoanálisis en Francia. Historia del psicoanálisis. Tesis psicoanalíticas. Estudios sobre la universidad.

\section{INTRODUÇÃO}

história da Psicanálise no ambiente universitário confunde-se com a própria
história da Psicanálise. Essa relação se encontra destacada por Freud, desde
Psicans primeiros escritos. A experiência universitária francesa com e sobre a
organizados de inserção na universidade. Na França, esse percurso é rico em
polêmicas, rupturas e personagens marcantes, mas também em diversidade de
pensamentos e interlocuções e já foi extensamente abordado (Roudinesco, 2009;
Mijolla, 2010). Essa inserção no ambiente universitário constitui um capítulo 
que merece ser explorado, sobretudo no que diz respeito à significativa produção oriunda das pesquisas e atividades acadêmicas.

Abordar a presença e efetividade da Psicanálise na universidade por meio da análise de suas produções tem sido uma estratégia muito utilizada nos mais diversos campos do conhecimento. Contudo, no campo da Psicanálise, tanto no Brasil como na França, praticamente inexistem teses e dissertaçôes tendo como objeto de investigação a produção científica sistematizada sobre e com a Psicanálise.

Considerando essa lacuna, realizamos um levantamento das teses produzidas nas instituições pioneiras na inserção da Psicanálise na universidade na França, as universidades Paris VII e Paris VIII, visando a explorar uma dimensão do atual panorama do campo psicanalítico universitário naquele país. Este artigo tem como objetivo retraçar parte da história da Psicanálise na universidade francesa, com destaque para produçóes psicanalíticas desenvolvidas em ambiente universitário. Por fim, buscamos estabelecer algumas articulaçôes com o campo psicanalítico brasileiro atual, visto que a relação entre os dois países tem sido de intenso intercâmbio e proximidade.

\section{APONTAMENTOS HISTÓRICOS}

As primeiras ideias psicanalíticas na França datam do início do século XX, precisamente 1914, quando Angelo Hesnard e Emmanuel Régis, divulgadores pioneiros, publicam o primeiro livro sobre o tema, La psychanalyse des névroses et des psychoses. Um ano antes, os mesmos autores lançam o artigo La doctrine de Freud et de son école na revista L'Encéphale (Roudinesco, 2009). Trata-se de um livro crítico em relação à Psicanálise e que exerceu grande influência nos precursores brasileiros da Psicanálise, tornando-se a primeira produção psicanalítica traduzida no Brasil, publicada em 1923 (Oliveira, 2002).

A entrada oficial e sistemática na universidade francesa tem início com o caminho trilhado por Daniel Lagache. Em 1937, nomeado professor em Strasbourg, ele cria os primeiros certificados de Psicopatologia e Psicologia Social na tentativa de unir Psicanálise e Psicologia. Sua meta é favorecer a análise leiga pela via universitária, introduzindo a clínica psicanalítica no curso de Psicologia. Em 1947, sucede a Paul Guillaume na cadeira de Psicologia Geral na Sorbonne; em 1955, ministra a disciplina de Psicologia Patológica, criada para ele nessa universidade. Juliette Favez-Boutonier assume seu lugar na disciplina de Psicologia Geral (Roudinesco, 2009). 
Anterior a esse movimento mais vigoroso de Lagache, Georges Heuyer, professor de psiquiatria infantil na Faculdade de Medicina de Paris, funda, em 1925, um Laboratório de Psicanálise, dirigido por Sophie Morgenstern. Em 1932, René Spitz, radicado na França, começa a ensinar Psicanálise e Psicologia do Desenvolvimento Infantil na Escola Normal Superior. Em comemoração aos 80 anos de Freud, em 1936, Henri Claude (um dos introdutores de Freud na França) preside uma cerimônia na Sorbonne, na qual Marie Bonaparte faz uma conferência sobre a obra de Freud. No mesmo ano, o filósofo Roland Dalbiez defende, também na Sorbonne, a primeira tese sobre Freud intitulada La méthode psychanalytique et la doctrine freudienne, publicado como livro em 1937 (Douville, 2009).

Contudo, bem antes desses acontecimentos, a história da Psicanálise na França é atravessada pelas relaçóes de Freud com a universidade francesa. Em 1885, ele obtém uma bolsa da Universidade de Viena para estudar em Paris, durante seis meses, na Salpêtrière, com o renomado neurologista Jean-Martin Charcot. O encontro com Charcot, suas pacientes histéricas e a teoria da histeria, é decisivo para o início da Psicanálise. Em 1889, Freud vai novamente à França, desta vez para Nanci, conhecer Hippolyte Bernheim e Ambroise-Auguste Liébault, representantes da chamada "Escola de Nanci", e suas teorias sobre a hipnose, método empregado por Freud (Mijolla, 2010).

No fim do século XIX, Janet, que posteriormente seria um grande crítico das ideias freudianas, em sua tese publicada sob a orientação de Charcot, cita várias vezes um artigo de Freud de 1893 (que viria a ser a Comunicação preliminar dos estudos sobre a histeria, publicado em 1895). Portanto, mesmo antes do livro pioneiro de Régis e Hesnard, as ideias de Freud já circulavam no meio médico e acadêmico. Mais tarde, as ideias de Janet iriam fazer uma espécie de barragem às ideias de Freud na França.

Os primeiros anos da Psicanálise na França, portanto, são marcados pelas críticas de Janet, pelas publicações já citadas e pela fundação, em 1926, da primeira associação psicanalítica da França, a Sociedade Psicanalítica de Paris (SPP), num ambiente marcado por conhecidas e importantes disputas. Após a Segunda Guerra Mundial, há um crescimento desse interesse, ao tempo em que começam decisivas cisões. A primeira delas ocorre em 1953. Daniel Lagache, Juliette Favez-Boutonier, Françoise Dolto e Jacques Lacan fundam a Sociedade Francesa de Psicanálise (SFP), reconhecida pela IPA em 1961 (Chiland, 1990).

Em 1963, uma nova cisão, e, no ano seguinte, Lacan funda sua própria escola, a Escola Freudiana de Paris (EFP), caracterizada por oferecer uma nova modalidade de transmissão. Além desta, é fundada também a Associação Psicanalítica da 
França (APF), pelo grupo de Lagache, Favez-Boutonier, Wladimir Granoff e Didier Anzieu, reconhecida em 1965 pela IPA. Em 1969, nova cisão, desta vez na EFP, tendo como pivô o dispositivo do passe. Assim, é fundado o Quatrième Groupe por Piera Aulagnier, François Perrier e Jean-Paul Valabrega. Em 1980, ocorre uma quarta cisão, quando Lacan dissolve sua escola. As dissidências internas levam à saída de alguns analistas e Jacques Alain-Miller com vários companheiros criam a Escola da Causa Freudiana, em 1981. Ainda na esteira dos acontecimentos de 1980, em 1998, instala-se uma crise na Associação Mundial de Psicanálise (AMP), com alguns analistas insatisfeitos em relação à postura de transmissão da Psicanálise realizada pela instituição. A crise culmina na criação da Internacional dos Fóruns do Campo Lacaniano e, posteriormente, da Escola de Psicanálise dos Fóruns do Campo Lacaniano. Ressaltamos que o movimento ocorreu em diversos países, não somente na França.

Mijolla e Mijolla-Mellor (2008) sugerem que a entrada da Psicanálise na universidade francesa surge em consequência das tantas cisões institucionais e, justamente após as duas maiores, a de 1953 e a de 1963, tem início uma presença de fato universitária da Psicanálise na França. Também Birman (2000) refere a inserção da Psicanálise na universidade como resultado, em parte, da crise de instituições psicanalíticas. A universidade seria, então, possivelmente um lugar no qual seria possível discutir criticamente a Psicanálise, longe da experiência transferencial, por vezes avassaladora, das instituições.

Antes da II Guerra Mundial, a Psicologia na França estava dividida entre a Filosofia, a Biologia e a Medicina, e, somente em 1947, é criada a Licence (curso de graduação) em Psicologia. Segundo Aguiar (2002), com base no pensamento de Anzieu (1979), a integração da Psicanálise à universidade francesa se dá, em grande medida, como suporte teórico e metodológico para a Psicologia clínica, em um momento de luta dos psicólogos por autonomia científica e exercício profissional independente. Uma relação de socorro mútuo e convergência de interesses se desenvolve entre Psicanálise e Psicologia na universidade francesa. A Psicanálise empresta à Psicologia apoio teórico e um modelo de prática e, em troca, a Psicologia serve como meio de divulgação da Psicanálise, o que observamos posteriormente nas teses analisadas. Já nessa época, muitos psicanalistas são professores em cursos de Psicologia.

Começa, então, um crescente interesse por parte de estudantes de Psicologia pela Psicanálise. Sem se submeter à autoridade de uma escola psicanalítica, os alunos adotam a Psicanálise como referência para suas práticas. Um fenômeno parecido ocorre no Brasil, pois uma das vias de entrada da Psicanálise na universidade foi e continua sendo o curso de graduação em Psicologia. Além 
disso, a Psicanálise é ensinada nos cursos de Psicologia, muitas vezes como alternativa teórico-clínica para práticas em Psicologia.

\section{PRODUÇÃO PSICANALÍTICA NAS UNIVERSIDADES PARIS VII E PARIS VIII}

Em que pese uma história de relações de mais de meio século, o marco oficial da entrada da Psicanálise na universidade francesa tem sido registrado como o momento da criação do Departamento de Psicanálise na Universidade Paris VIII e do Laboratório de Psicanálise na Universidade Paris VII, ambos no ano de 1968, tornado célebre na história da França devido a vigorosos movimentos estudantis e operários que culminaram em importantes reformas no ensino. Graças às transformaçôes sociais em curso, a universidade se torna mais acessível e os estudantes passam a ter posição ativa na apropriação do conhecimento, com mudanças expressivas na relação com os professores.

Na mesma época, surge uma Unidade de Ensino e Pesquisa ${ }^{1}$ (UER) de Ciências Humanas e Clínicas que se vincula à Universidade Paris VII. Em seu programa, encontra-se o ensino sobre a clínica freudiana. Em 1969, Jean Laplanche se junta a essa UER, criando um Laboratório de Psicanálise e Psicopatologia e introduzindo, pela primeira vez, o significante "psicanálise" no ensino universitário. O programa se divide em quatro eixos de pesquisa: Psicopatologia Psicanalítica, Psicanálise Aplicada, Teoria da Psicanálise e História da Psicanálise e da Prática Freudiana. Alguns dos professores são filiados à AFP.

Laplanche cria o Diplômes d'Études Approfoundies (DEA) ${ }^{2}$ de Psicopatologia Clínica e Psicanálise em 1974 e, no ano seguinte, obtém autorização para abrir o doutorado na mesma área. Somente em 1980, esse doutorado recebe o nome de Doutorado em Psicanálise, marcando a especificidade e autonomia do campo.

Em 1975, começa a ser editada, pelo Laboratório de Psicanálisee Psicopatologia, a revista Psychanalyse à l'université, com tiragens trimestrais, na qual Laplanche publica seus seminários e artigos de colaboradores próximos. No primeiro número, Laplanche afirma que o recém-criado doutorado não seria um ensino puramente teórico e nem propagaria a Psicanálise como doutrina dogmática, mas teria como objetivo, a partir da pesquisa, ser um "fermento teórico", um centro de confrontação, elaboração e publicação (Laplanche, 1975).

\footnotetext{
1 Unité d'Ensignement et Recherche. Após 1968, as antigas cátedras são substituídas pelas UER, mais autônomas e pluridisciplinares. Posteriormente, em 1984, as UER são transformadas em UFR (Unité de Formation et Recherche - Unidade de Formação e Pesquisa). A UFR associa os departamentos de formação e os laboratórios de pesquisa na universidade francesa.

2 Antigo diploma necessário para entrada no doutorado na universidade francesa.
} 
A revista torna-se um veículo de divulgação da Psicanálise na universidade e assim permanece durante 19 anos, até o seu último número, em 1994. Os artigos contemplam assuntos diversos, como Psicanálise e literatura, psicose, psicopatologia, psicossomática; prática clínica, abordando transferência contratransferência e clínica com crianças e adolescentes. Alguns discutem a Psicologia do ego e suas relações com a Psicanálise. Apenas cinco textos abordam a Psicanálise lacaniana.

$\mathrm{Na}$ seção Documentos e Pesquisa, retratam-se os temas de investigação da época. Além dos tradicionais do campo como psicose, histeria e psicossomática, também presentes nos artigos, e da interface com a literatura, encontram-se estudos sobre assuntos recentes, mas já apresentados e debatidos pelas ciências e pelos movimentos sociais da época, como neonatologia, em 1977; reprodução assistida e infertilidade, a partir de 1982; a questão da paternidade/maternidade em homossexuais, em 1985; psicofarmacologia, em 1986; pacientes com HIV, pacientes com doença de Alzheimer, em 1991; mudança de sexo, em 1992. A revista publica também conferências e trabalhos de colóquios e jornadas científicas realizados em universidades francesas e do exterior bem como traduções inéditas de textos de Freud, Klein, Winnicott, entre outros.

Em Vincennes, o processo se constitui de modo diverso, mais vinculado à vertente lacaniana. A Psicanálise não constituía uma UER própria, sendo ligada à UER de Filosofia, ou seja, um curso teórico no interior da formação filosófica. O Departamento de Psicanálise, presidido por Serge Leclaire, começa a funcionar em 1969. Seu objetivo é contribuir para o estudo, a pesquisa e a elaboração da Psicanálise (Leclaire, 1985). Para ele, a universidade representa uma abertura de horizontes para o lacanismo e mesmo para o pensamento psicanalítico de forma geral, que seguia um caminho de dogmatização

Em 1968-1969, quando criei em Vincennes o primeiro "departamento de psicanálise” do mundo, fizeram-me compreender e sentir no âmago do comitê central (diretório) da EFP que se tratava de uma transgressão sacrílega, o que não impediu essa mesma instância de trabalhar intensamente para recuperar internamente o dito departamento [. . .] que, vale ressaltar, é a única instituição que atravessou sem danos a dissolução e prosperou, como sabemos, em Saint Denis Paris VIII (Leclaire, 1985, pp. 319-320, tradução nossa).

Segundo Roudinesco (2009) e Safouan (2013), e de acordo com o trecho da citação acima de Leclaire, Lacan não aprova a experiência de Vincennes, mas, ao mesmo tempo, sabe que se trata de iniciativa importante para a expansão de seu ensino. As concepções de Lacan sobre o ensino da Psicanálise e sobre sua inserção universitária são controversas e polêmicas. Para ele (Lacan, 1957/1998) ${ }^{3}$, não 
seria possível um mero ensino profissional, mas uma transmissão, antecipando em muitos anos críticas que outros campos farão sobre a formação universitária de modo geral como excessivamente voltada para a habilitação profissionalizante. Há aí uma severa crítica ao modelo cientificista, reproduzido de modo universalizante, e cuja matriz epistêmica é a ciência cartesiana, atualizada com o positivismo comtiano.

A proposta de ensino que Lacan traz para a universidade, e é importante frisar que, embora crítico, ele não descarta a universidade, parte de outro referencial epistemológico, não cartesiano. $\mathrm{O}$ que se pode transmitir do que se ensina é um desejo de saber, e esse desejo somente pode ser transmitido como falta, para que cada sujeito possa fazer sua produção, marcando um estilo próprio. A Psicanálise lacaniana amplia a ideia freudiana de desejo, conceituando-o como desejo de saber sobre a falta do sujeito, sempre incompleto, impossível de ser apreendido e, portanto, ensinado, mas que pode ser transmitido não todo, na relação transferencial de trabalho. É esse saber que a Psicanálise pode oferecer à universidade. No entanto não podemos esquecer que tais críticas são dirigidas a uma universidade fechada e doutrinária, na França, antes dos eventos de Maio de 1968. Assim como ele criticou a universidade sem se afastar dela, também promoveu um vigoroso e renovador movimento da instituição psicanalítica, ao voltar-se contra a formação da IPA, rígida, disciplinar e dogmática.

Em meio a esse embate, Leclaire pede demissão do Departamento de Psicanálise e, em 1974, Jacques-Alain Miller assume a direção com o apoio de Lacan, criando, dois anos, depois um Doutorado em Psicanálise. Safouan (2013) chega a afirmar que Lacan esperava mais da universidade do que de sua própria escola, envolta em disputas e problemas institucionais. $\mathrm{O}$ departamento permaneceu funcionando, apesar desse início tumultuado e das cisões do movimento lacaniano. Em um texto intitulado Talvez em Vincennes... (Lacan, 1975/2003), ele reconhece essa experiência quando diz:

Talvez em Vincennes venha a se reunir os ensinamentos em que Freud formulou que o analista deveria apoiar-se, reforçando ali o que extrai de sua própria análise, isto é, saber não tanto para que ela serviu, mas de que se serviu. [. . .] Agora não se trata somente de ajudar o analista com ciências propagadas à moda universitária, mas de que essas ciências encontrem em sua experiência uma oportunidade de se renovar (Lacan, 1975, p. 316).

Este percurso histórico favorece uma compreensão contextualizada não somente da atual inserção da Psicanálise na universidade francesa, com suas articulações a diversos campos, mas nos ajuda a examinar, por meio de aproximaçôes e contrastes, a situação da Psicanálise na universidade brasileira. 
$\mathrm{Na}$ França, assim como na maioria dos países europeus e norte-americanos, não existe curso de mestrado tal como estruturado no Brasil. Após três anos de graduação (licence), o estudante continua seus estudos no master professionel (M1) ou master recherche (M2), sendo este último indispensável para entrada no doutorado.

Atualmente, o Departamento de Psicanálise da Universidade Paris VIII, vinculado à Escola da Causa Freudiana, concede os diplomas de master e doutorado e pertence a uma UFR que reúne os departamentos de Ciências da Educação, Comunicação e Psicanálise. Em Paris VII, a antiga UER de Ciências Humanas e Clínicas torna-se a UFR de Études Psychanalytiques, a partir de 2011. Ela é a única UFR da França específica em Psicanálise, oferecendo uma licence em Psicologia, master e doutorado em Psicanálise. Esses diplomas são vinculados, do ponto de vista disciplinar, à Psicologia, de acordo com o Conselho Nacional das Universidades (CNU), instância que regulamenta a carreira de professor universitário na França e na qual a Psicanálise é reconhecida como uma das orientações da Psicologia. Essa UFR é a única que ministra uma formação de psicólogos clínicos orientada pela Psicanálise, o que configura uma exceção naquele país. A UFR é também responsável pela edição de Recherches en Psychanalyse, revista fundada em 2004 e ligada à École Doctorale Recherches en Psychanalyse et Psychopathologie. Essa universidade tem o mérito de consagrar duas revistas à interface Psicanálise e universidade.

\section{PANORAMA ATUAL DA PSICANÁLISE NA UNIVERSIDADE FRANCESA: TESES}

Como efeito dos movimentos sociais do fim da década de 1960, a universidade francesa passa por grande reestruturação, tornando-se mais acessível a um maior número de alunos. Ao contrário do que acontecia anteriormente nas universidades, com suas rígidas estruturas, pautadas na soberania do professor e na reprodução social (Bourdieu \& Passeron, 1992), os estudantes passam a ter algum protagonismo. Examinando tais transformações, Hoffmann e Birman (2011) afirmam que a universidade francesa se desenvolve em torno de três eixos: cidadania, pesquisa e formação. A cidadania é contemplada no amplo acesso, sobretudo de classes populares. A pesquisa se torna o foco, por meio dos laboratórios que descentram a figura do professor. O laboratório apoia a graduação e garante o ensino, eixo da formação, agora centrado na pesquisa que passa, indiscutivelmente, a "porta-voz" estruturante da universidade, segundo os autores. Ao posicionar a pesquisa como ponto de partida e de ancoragem institucional, desloca-se a posição de docentes e de estudantes, e instaura-se 
um novo espaço de trocas, com lugares menos personalizados ou centrados na figura do mestre. A pesquisa coloca o saber em uma posição terceira na relação professor-aluno, fomentando uma postura ativa pela apropriação do conhecimento, não cabendo mais simplesmente a reprodução de informações e o acúmulo de conhecimentos. Essa nova perspectiva de pesquisa tem como eixo a pluridisciplinaridade, que questiona a organização disciplinar da universidade, devendo o pesquisador enriquecer os modelos de pesquisa existentes. Com isso, na visão dos autores, há uma abertura epistemológica à Psicanálise que, na perspectiva da pluridisplinaridade, adquire papel indispensável na constituição da nova universidade francesa.

Visando a demonstrar essa importante dimensão da pesquisa na universidade, apresentamos, em trabalho anterior (Fonteles, 2015), uma investigação tendo como objeto as teses em Psicanálise produzidas no Brasil para, a partir desses dados empíricos, estabelecer relações sobre o campo psicanalítico universitário brasileiro. Uma pesquisa próxima, mas em menor proporção, foi conduzida na França, junto às teses produzidas pelas Universidades Paris VII e Paris VIII. Essas são as duas universidades francesas com tradição histórica de inserção da Psicanálise, como já apresentado, além de serem as únicas a ter doutorado específico em Psicanálise. O período escolhido, em ambos os países, abrange os anos de 1987 a 2012.

No ambiente francês, realizamos uma busca em um indexador oficial de teses (https://www.theses.fr/) que agrega todas as teses defendidas e as que estão em vias de preparação na França. Os trabalhos foram capturados por meio dos descritores "Psychanalyse" e "Psychanalytique", presentes seja no título, nas palavras-chave ou no resumo. Após seleção e leitura dos resumos, coletamos dados como título, autor, ano de defesa, instituição, área de conhecimento, temática, método e referenciais teóricos. A partir da compilação desses dados, foi possível tecer algumas observações sobre aquele contexto universitário da Psicanálise. Ademais, os dados históricos anteriormente discutidos ajudam a traçar esse panorama atual da Psicanálise na universidade.

Além do sítio consultado, levamos em consideração a seção de teses defendidas, registrada na revista Psychanalyse à l'Université, de forma a complementar as informações. A pouca sistematização de registros é uma realidade, sobretudo quando se trata de períodos anteriores à informatização de dados. Portanto os resultados obtidos refletem apenas dados disponíveis sobre as teses depositadas dessas duas universidades. 
Foram encontradas 381 teses no período de 1987 a 2012, conforme aponta o gráfico a seguir.

\section{Gráfico 1 - Distribuição cronológica de teses em Psicanálise na França (1987-2012)}



Fonte: elaborado pelas autoras.

Apesar de este estudo concentrar-se na produção de apenas duas instituições, sabemos que a Psicanálise vem passando, há pelo menos dez anos, por um período de intensa contestação na França, aliado a um crescimento da Psicologia cognitiva. Um primeiro olhar evidencia a presença de claras ondas de oscilação nessa produção. Há um momento de pico produtivo, no ano de 1993, com 14 teses, seguindo-se imediatamente um período de três anos de baixíssima produção, sendo que o ano de 1996 apresenta apenas uma tese defendida.

Entre as 381 teses, 315 são produzidas na Universidade Paris VII e 66 na Paris VIII. Uma das explicações para essa diferença pode ser a vinculação do doutorado de Psicanálise da Universidade Paris VII à Psicologia, o que atrai uma maior quantidade de alunos e reflete ligaçôes acadêmicas históricas desses dois campos, como apresentado anteriormente, visto que uma das vias de entrada da Psicanálise nessa universidade se dá pela Psicologia, tendo como ponto de partida a experiência de Lagache e Laplanche. $\mathrm{Na}$ França, os concursos para docente nas universidades priorizam os percursos acadêmicos na área do concurso; assim, uma vaga para professor em Psicologia será preenchida por um docente que tenha percurso acadêmico, isto é, doutorado em Psicologia.

Entre as teses, 245 são produzidas nos dois doutorados específicos em Psicanálise. As outras 136 estão divididas em outras áreas, conforme gráfico a seguir. 


\section{Gráfico 2 - Distribuição das teses por área de conhecimento}

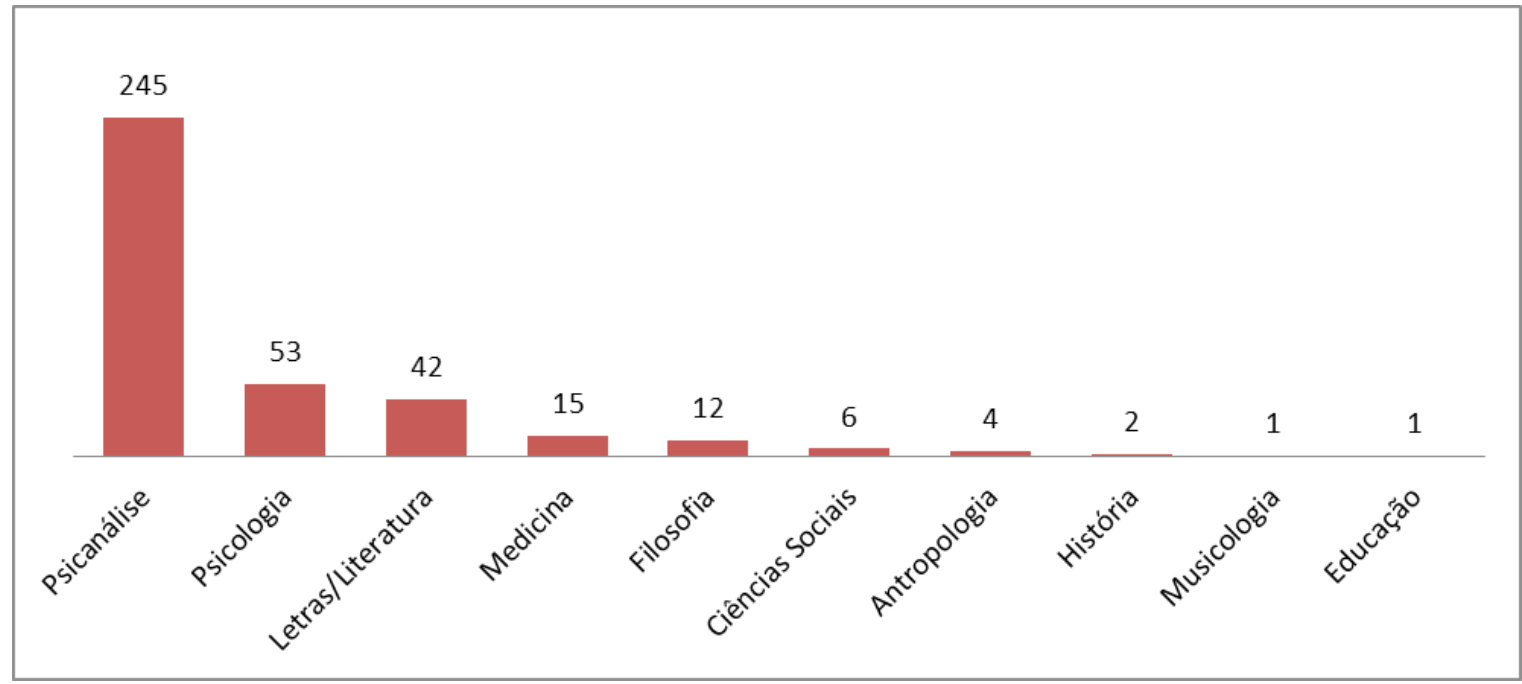

Fonte: elaborado pelas autoras.

Há uma elevada produção no domínio específico da Psicanálise. A segunda área, como esperado, é a Psicologia, seguida de Letras, Literatura, Medicina e Filosofia, áreas tradicionais de interlocução com a Psicanálise. Historicamente, a Psicologia é, sem dúvida, uma porta de entrada para a Psicanálise na universidade. No entanto um grande número de teses na área da Psicanálise pode indicar uma maior autonomia desse saber no campo universitário, já que os doutorandos não mais precisariam buscar caminhos em outros campos para inserir a produção em Psicanálise.

Laplanche (2004) argumenta que a Psicanálise na universidade pode estender-se à Psicologia, à Psicopatologia e às Ciências Humanas em geral, ainda que permaneça na universidade como disciplina autônoma. Com doutorado próprio, a Psicanálise, pela primeira vez, é reconhecida como domínio autônomo, marcando sua unidade e especificidade em relação à Psicologia. Se, no início, a Psicanálise precisou da Psicologia e de outros campos, como a Medicina, para ganhar espaço, atualmente o campo psicanalítico está mais bem constituído e não apenas produz investigaçóes próprias como atravessa outros campos em diálogo interdisciplinar.

Em relação ao conteúdo das teses, mais de $50 \%$ do referencial teórico é freudo-lacaniano. Encontramos poucas teses referenciadas em autores das linhas anglo-saxônicas, como Melanie Klein (4), Ferenczi (3), Winnicott (2) e Ballint (1). Trata-se de um dado esperado, tendo em vista a predominância do referencial lacaniano na Psicanálise francesa, sendo também o referencial que pauta o ensino nas duas universidades pesquisadas. $\mathrm{O}$ referencial lacaniano justifica-se, sobretudo na Paris VIII, em razão da presença do próprio Lacan na 
implantação do Departamento de Psicanálise, retomando discussões freudianas sobre a presença desse saber não universitário na universidade. Destacamos ainda a presença de cinco teses que versam sobre a obra de um único autor; no caso Ferenczi, Abraham, Fairbairn, Devereux, Castoriadis.

Em relação ao método, a maior parte das teses não faz referência no seu resumo ao delineamento metodológico seguido. Deduzimos, pela leitura dos resumos dos trabalhos que não autodeclaram seu método, que se trata de pesquisas teóricas e estudos de caso, métodos tradicionalmente usados em pesquisas psicanalíticas. Entre os que declararam, há uma predominância de estudos de casos; 18 teses usaram entrevistas, uma referiu aplicação do teste Rorschach e outra empregou grupos Ballint.

Uma tese não é escrita apenas para os leitores da área, sobretudo numa época de valorização da interdisciplinaridade e da elaboração de trabalhos conjuntos entre diversos campos de saber. $\mathrm{O}$ resumo de uma tese, caso específico do material de pesquisa aqui trabalhado, é uma apresentação da tese ao mundo acadêmico mais amplo, uma espécie de "cartão de visitas" da investigação para a comunidade científica e, em termos gerais, deveria conter todas as informações necessárias para o bom entendimento do trabalho. No entanto a realidade com a qual nos deparamos foi de ausência de muitos resumos nos sites indexadores das teses e ausência das informações buscadas (método, referencial e tema) nos resumos encontrados.

Em relação aos temas de pesquisa, ressaltamos a dificuldade em delimitar uma temática com base na leitura dos resumos, sobretudo pelo caráter indissociável entre teoria e clínica, mas pudemos compilar temáticas mais frequentes. Antes, observamos que as duas universidades recebem estudantes de diversos países, o que leva a temas bem específicos de pesquisa, como o mal de Alzheimer na Coreia, interação mãe/criança autista no Vietnã, violência e agressividade em adolescentes do Irã, a Psicanálise na China, atribuição do nome no sul do Benim, o feminino na cultura chinesa, história da Psicanálise no Brasil (especificamente em São Paulo, Rio de Janeiro e Rio Grande do Sul), na Argentina, na Rússia e em Israel.

Nesse levantamento, encontramos 32 teses de pesquisadores brasileiros, o que mostra uma relação de interesse Brasil-França. Esse interesse é antigo, como percebemos no estudo realizado por um grupo da École de Hautes Études en Sciences Sociales (EHESS): um levantamento de teses defendidas em Ciências Sociais e Humanas que versa sobre o Brasil no período de 1823 a 1999 e, posteriormente, de 2000 a 2011 (Le Centre de Recherches sur le Brésil Colonial et Contemporain, 2015). As áreas que concentram teses sobre o Brasil são: 
Economia, seguida de Sociologia, Geografia e Literatura. A Psicologia conta com 55 teses em todo o período. Dentre estas, destacam-se oito em Psicanálise, realizadas nas Universidades Paris VII (3), Paris XIII (2), Paris X (2) e Paris V (1), sobre temas como carnaval, literatura de cordel, crianças de rua, atendimento a adolescentes, crime passional e Direto Penal brasileiro, história da Psicanálise no Brasil e um estudo etnopsicanalítico sobre a experiência da Ayahuasca.

Voltando aos temas das teses francesas, percebemos a interlocução da Psicanálise com diversos campos de saber. No plano da interação entre Psicanálise e Filosofia, destacamos diálogos da teoria psicanalítica, com as obras de filósofos como Kierkegaard, Kant, Nietzsche, Foucault, Heidegger, Emmanuel Levinas, Platão, Lyotard, Wittgenstein e Deleuze, para citar os que foram referenciados. Das 12 teses em Filosofia, 11 estão em Paris VIII, lugar de históricas relações entre Filosofia e Psicanálise e sob a orientação, em sua maior parte, de Alain Badiou, um dos fundadores do Departamento de Psicanálise da instituição, inicialmente vinculado a uma UER de Filosofia. Nessa universidade, a Psicanálise se inseriu de modo mais desvinculado da Psicologia, por meio de um modelo inovador que congregou professores como Michel Foucault, Gilles Deleuze o próprio Alain Badiou, entre outros.

Uma área de interlocução que se destaca com um grande número de teses é Letras e Literatura, em sua maioria na Paris VII, com teses sobre leituras freudo-lacanianas de obras literárias, em geral trazendo questôes epistemológicas da aplicação da Psicanálise à literatura, e outras relacionadas à produção de escritores e artistas como Valéry, Zola, Sade, Alain Robbe-Grillet, André Pieyre de Mandiargues, Boris Vian, Roland Barthes, Balzac, Stendhal e Isabelle Eberhardt para citar os autores francófonos. Na literatura anglófona, destacamos análises das obras de Carson McCullers, Nathaniel Hawthorne, Shakespeare e T. S. Eliot; na italiana, Giuseppe Berto e Ottiero Ottieri; na alemã, Goethe e o próprio Freud. Encontramos ainda teses sobre obras do árabe Ibn Arabi, do russo Varlam Chalamov e também a literatura brasileira, com uma tese sobre o feminino, pela ótica de Clarice Lispector. $\mathrm{Na}$ interface com as Artes, encontramos teses que versam sobre o ato criativo, estudo sobre a obra de Joan Miró, relações entre Psicanálise e Surrealismo, o teatro de Molière e de Paul Claudel.

No entanto mais da metade das teses dirigem-se à clínica psicanalítica, envolvendo tanto a teoria da clínica, quanto questôes em torno da Psicopatologia, com destaque para as psicoses, um dado coerente se considerarmos que a clínica sempre foi e continua sendo o lócus primordial das pesquisas em Psicanálise. A Paris VII, por exemplo, destaca-se por suas pesquisas em psicopatologia psicanalítica, o que dá nome a seu doutorado: École Doctorale Recherches 
en Psychanalyse et Psychopathologie, dando continuidade às pesquisas de seu laboratório pioneiro, o Laboratório de Psicanálise e Psicopatologia.

A Medicina é também um campo tradicional de interlocução com a Psicanálise. O doutorado da Paris VII está vinculado ao Laboratório Centre de Recherches Psychanalyse, Médicine et Société (Centro de Pesquisas Psicanálise, Medicina e Sociedade). Ressaltamos aí teses sobre os seguintes temas: hospitalização, cuidados paliativos, câncer, mal de Alzheimer, diabetes, doenças psicossomáticas (psoríase, alergias, lúpus), bem como sobre pacientes com dor crônica. Encontramos pesquisas com aplicação de testes neuropsicológicos, mostrando interação com as chamadas neurociências. Destacamos ainda teses sobre o corpo: modificações corporais, corpo na psicose, dor crônica, transexualismo e mudança de sexo, bem como transtornos alimentares: anorexia, bulimia e transtornos alimentares no bebê.

Temas do social e da cultura comparecem: crime passional, violência, delinquência, tortura, exílio, refugiados de guerra, luto, Psicanálise nas instituições, história da Psicanálise, relação Psicanálise e ciência, suicídio, religião e espiritualidade. A educação conta com apenas um trabalho sobre a noção de autoridade e a relação professor-aluno. Encontramos uma tese em Musicologia sobre as estruturas do gozo musical.

Tais dados, apenas descritivos, podem traçar um esboço das pesquisas em Psicanálise na universidade, temáticas trabalhadas e que interessaram aos pesquisadores franceses no período. Podemos perceber também alguns indícios de como este campo funciona, com base na diversidade de temas e interlocuções, considerando o histórico de inserção da Psicanálise na universidade ao longo dos anos na França.

\section{5. À GUISA DE CONCLUSÃO}

A Psicanálise na universidade francesa tem seu status bem estabelecido e, podemos dizer, autônomo, haja vista os dois departamentos de Psicanálise e seu papel decisivo para a história da Psicanálise na universidade, não apenas naquele país. É a partir desse lugar bem estabelecido que a Psicanálise vai se deslocar, fecundando campos conexos. Tal situação a encontramos em Freud, no texto $O$ interesse da psicanálise. Nele, Freud (1913/2012) explicita claramente uma visão interdisciplinar, não apenas decorrente da gênese desse campo, mas também por seu genuíno interesse pelo diálogo com os mais diversos campos, por ele chamados de "ciências não psicológicas" (p. 343). Seu objetivo nesse texto era mostrar como a Psicanálise pode interessar a outros campos estabelecendo "extensos 
laços” (p. 363). Desse modo, Freud pôde demonstrar ganhos de conhecimento que a Psicanálise aporta para outras ciências. Corroborando com Freud, Mijolla e Mijolla-Mellor (2008) dizem que a Psicanálise encontra seu lugar perante as outras ciências, e é desse lugar que ela pode interrogar e ser interrogada, estando em posição de interlocutora, fazendo avançar pesquisas por meio do confronto com a noção de inconsciente e com seu método.

A dimensão interdisciplinar parece ser uma característica assegurada pela universidade francesa, sobretudo em um momento de contestação da Psicanálise na França. É possível afirmar que a universidade proporciona lugares para ampliação do debate psicanalítico para além das escolas, por meio de investigações sobre diversos temas dentro e fora da Psicanálise, em diversos campos.

Retomar a experiência francesa é importante para examinar, por contraste, a experiência brasileira que conhece um histórico de relações com a França. A Psicanálise está presente nos espaços universitários brasileiros, desde o início do século XX, pela via da Medicina e depois da Psicologia e, a partir da década de 1980, está presente também na pós-graduação, de forma efetiva, com a criação de programas específicos: há quatro PPG em Psicanálise atualmente. A vinculação histórica à Psicologia também é fato, embora as agências brasileiras (Capes e $\mathrm{CNPq}$ ) não reconheçam, em seus domínios formais, o campo da Psicanálise, seja como área autônoma ou como subárea da Psicologia. Além disso, não existem cursos de graduação em Psicologia orientados pela Psicanálise, como ocorre no ambiente universitário francês.

De acordo com Birman (1988), duas são as visões da Psicanálise brasileira em relação à francesa: valorizar o que se faz na França, creditando a diferença a um suposto atraso brasileiro, ou não aceitar a Psicanálise francesa, tendo em vista que boa Psicanálise seria aquela proveniente da tradição anglo-saxônica. Muitos psicanalistas brasileiros empreenderam suas formações acadêmicas e psicanalíticas na França, retornado ao Brasil e trazendo as ideias da Psicanálise francesa, sobretudo lacaniana. No entanto, hoje, a Psicanálise brasileira pode falar em nome próprio, afastando-se de uma mentalidade colonizada, sendo essa conquista permitida também pela inserção universitária (Birman, 2000).

As produções científicas em Psicanálise, tanto no Brasil como na França, apresentam características semelhantes, no que diz respeito ao predomínio do referencial freudo-lacaniano, aos temas primordialmente teórico-clínicos, à não explicitação dos métodos, à variada interlocução com outros campos de saber. No Brasil, a maior parte das teses encontra-se em Psicologia e não em programas específicos de Psicanálise, ao contrário da França. No entanto, há, no Brasil, uma dispersão em diversas áreas, as mesmas encontradas na França (Psicologia, 
Letras, Literatura, Filosofia, Medicina). Relações próximas e conflituosas com a Psicologia são marcas características, tanto no ambiente brasileiro (Fonteles, 2015) quanto no sistema universitário francês.

Este trabalho não pretendeu ser um estudo comparativo da produção dos dois países, mas apresentar um panorama da Psicanálise na universidade francesa, no sentido de reconhecer especificidades e provocar olhares comparativos. A investigação por nós conduzida no ambiente universitário brasileiro (Fonteles, 2015) abrangeu todas as teses autodeclaradas em Psicanálise, em todas as instituiçôes de ensino superior, ao passo que a pesquisa francesa contempla apenas duas universidades (Paris VII e Paris VIII), o que limita a análise e não reflete a realidade francesa por completo.

A pesquisa, juntamente com o ensino e a extensão, é eixo estruturante do fazer universitário. É também uma dimensão original e necessária à experiência da Psicanálise, desde os primeiros escritos de Freud. Corroboramos o pensamento de Laplanche (2004), para quem a pesquisa psicanalítica na universidade pode trazer uma dupla garantia: rigor e ousadia do debate e campo epistemológico independente e de pleno direito. 


\section{REFERÊNCIAS}

Aguiar, F. (2002). A Psicanálise e a Psicologia na universidade francesa: relação de conflitos e de mútuos interesses. Estudos de Psicologia, 7(1), 133-142.

Anzieu, D. (1979). La psychanalyse au service de la psychologie. Nouvelle Revue de Psychanalyse, 20, 59-75.

Birman, J. (1988). Percursos na história da Psicanálise. Rio de Janeiro: Taurus.

Birman, J. (2000). Entrevista com Joel Birman Revista Latino-Americana de Psicopatologia Fundamental, 4(2), 168-172.

Boudieu, P. \& Passeron, J-C. (1992). A reprodução: elementos para uma teoria do sistema de ensino (3a ed.). Rio de Janeiro: Francisco Alves.

Chiland, C. (1990). Homo psychanalyticus. Paris: PUF.

Douville, O. (2009). Chronologie de la psychanalyse du temps de Freud (18561939). Paris: Dunod.

Fonteles, C. S. L. (2015). Psicanálise e universidade: uma análise da produção acadêmica no Brasil. (Tese de Doutorado). Universidade Federal da Bahia Université Paris Diderot, Programa de Pós-graduação em Psicologia, Paris 7 , Salvador.

Freud, S. (1913). O interesse da Psicanálise. Obras Completas (Vol. 11, pp. 328363). São Paulo: Companhia das Letras, 2012. (Publicado originalmente em 1913).

Hoffmann, C. \& Birman, J. (2011). L'autonomie des universités et la nouvelle condition étudiante. La célibataire, 23, 55-62.

Lacan, J. (1957). A Psicanálise e seu ensino. In Escritos (pp. 438-460). Rio de Janeiro: Jorge Zahar, 1998. (Publicado originalmente em 1957).

Lacan, J. (1975). Talvez em Vincennes... In Outros escritos (pp. 316-318). Rio de Janeiro: Jorge Zahar, 2003. (Publicado originalmente em 1975).

Laplanche, J. (1975). Doctorat de 3 ème cycle: psychopathologie clinique et psychanalyse. Psychanalyse à L'Université, 1, 213-215.

Laplanche J. (2004). Pour la psychanalyse à l'Université. Recherches en Psychanalyse, 1(1), 9-13. 
Le Centre de Recherches sur le Brésil Colonial et Contemporain. (2015). Paris: l'Ecole des Hautes Études em Sciences Scieales. Recuperado a partir de http:// crbc.ehess.fr

Leclaire, S. (1985). Parcours d'un psychanalyste. Entretien avec Synapse. In S. Leclaire, Écrits pour la psychanalyse: Demeures de l'ailleurs 1954-1993 (Vol. 1, pp. 313-322). Paris: Seuil/Arcanes.

Mijolla, A. (2010). Freud et la France. Paris: PUF.

Mijolla, A. \& Mijolla-Mellor, S. (Orgs.) (2008). Psychanalyse. Paris: PUF.

Oliveira, C. L. M. V. (2002). Os primeiros tempos da psicanálise no Brasil e as teses pansexualistas na educação. Ágora, 5(1), 133-154.

Roudinesco, E. (2009). Histoire de la Psychanalyse en France: Jacques Lacan, esquisse d'une vie. Paris: Fayard.

Safouan, M. (2013). La Psychanalyse: science, thérapie et cause. Paris: Thierry Marchaisse. 